\title{
ОПТИМАЛЬНЫЕ ПАРАМЕТРЫ УДОБРЕНИЙ ПРОЛОНГИРОВАННОГО ДЕЙСТВИЯ И ОПЫТ КОМПЛЕКСИРОВАНИЯ ОТХОДОВ ПЕРЕРАБОТКИ К-Мg РУД С ОТХОДАМИ ОБОГАЩЕНИЯ ФОСФОРИТОВ
}

\author{
А.Ф. СМЕТАННИКОВ, Д.В. ОНОСОВ, Е.Ф. ОНОСОВА \\ Горный институт УрО РАН, г. Пермь
}

\begin{abstract}
Аннотация: В статье освещаются вопросы утилизации отходов переработки K-Mg руд, использования продуктов переработки в качестве комплексных удобрений пролонгированного действия и необходимые параметры для их применения. Приводятся результаты смешивания отходов переработки $\mathrm{K}-\mathrm{Mg}$ руд и отходов обогащения фосфоритов (эфелей). Показана комплексность полученных удобрений, характеризующаяся наличием сочетанием питательных компонентов (NPK), мелиорирующих компонентов и микроэлементов, выполняющих роль микроудобрений.

Природная часть мелиорирующих компонентов разрушается при высокотемпературном обжиге, но замещается новообразованиями, имеющими более высокие мелиорирующие свойства.

Установлен минеральный состав конечных продуктов утилизации комплексных удобрений (огарков) и состав примесей микроэлементов, используемых как микроудобрения. На основе полученных результатов сделаны рекомендации по направлению дальнейших исследований.
\end{abstract}

Ключевые слова: комплексные удобрения пролонгированного действия; эфели; фосфориты; обогащение; высокотемпературный обжиг; огарки; минеральные новообразования; микроэлементы; микроудобрения.

\section{Введение}

Плодородие почв зависит от содержания питательных компонентов, азота, фосфора и калия (NPK), содержания микроэлементов $(\mathrm{Cu}, \mathrm{Zn}$ и др.) с функцией микроудобрений и мелиорирующих компонентов. Основными минералами, обладающими мелиорирующими свойствами, являются доломит (для раскисления кислых почв) и гипс (для сульфатизации щелочных почв). Гипс можно рассматривать как аккумулятор влаги в зимних условиях и как донор влаги в засушливых летних условиях путем дегидратации гипса и превращения его в ангидрит.

Мелиорирующие компоненты крайне важны для стабилизации химических и агрофизических свойств почв, в частности их кислотности или щелочности, которые зависят от наличия в почве минералов-мелиорантов, доломита, влияющего на кислотность почвы, и сульфатов кальция, влияющих на щелочные свойства почв. От необходимого и достаточного наличия всех упомянутых компонентов напрямую зависит плодородие почв. Все эти свойства связаны либо с природным плодородием почв, либо с восстановлением плодородия путем внесения недостающих компонентов и, в первую очередь, удобрений. Острая необходимость внесения всего комплекса питательных компонентов существует для почв Пермского края и других северных регионов России, где более 70\% почв являются кислыми дерново-подзолистыми.

Все упомянутые свойства характерны для отходов переработки K-Mg руд (шламов).

Ранее ГИ УрО РАН выполнялась программа по утилизации шламов с целью извлечения благородных металлов.

В процессе исследований было установлено, что шламы по составу полностью отвечают вещественному комплексу, описанному выше, и могут быть использованы в качестве комплексных удобрений пролонгированного действия. В шламах присутствует весь необходимый спектр компонентов - удобряющих (K, Сa), мелиорирующих доломит, гипс, ангидрит и микроудобрения. Определенный диссонанс вносит отсутствие двух компонентов из триады питательных: это фосфор (Р) и азот $(\mathrm{N})$. 
Препятствием для прямого использования шламов как комплексных удобрений является присутствие в них жидкой фазы, содержащей хлориды K и Na и техногенные компоненты (амины, полиакриламид, неонол и др.). Разработанная технология переработки шламов включала процессы обогащения (обезвоживание, частичное обессоливание, сушку и грануляцию). Для переработки концентрата обогащения (гранулята) был разработан высокотемпературный обжиг.

В процессе обжига все техногенные компоненты отжигались, а хлориды и часть минералов нерастворимого в воде остатка (Н.О.) разрушались, и на их базе формировались минеральные новообразования, имеющие функцию питательных компонентов и мелиорантов. Все преобразования относились к твердофазным, без участия растворов. Конечный продукт (огарок) представляет собой комплексные удобрения пролонгированного действия [1,2]. При испытаниях огарка в качестве удобрений пролонгированного действия были отмечены особенности состава, изменение которых зависело от параметров получения огарка, связанных с разными температурными режимами обжига.

\section{Результаты исследований}

Испытания комплексных удобрений пролонгированного действия из отходов переработки K-Mg руд (шламов) показали, что в комплексе с добавками недостающих питательных компонентов (NP) показатели урожайности не хуже, чем с традиционными (NPK) удобрениями [3]. C целью достижения оптимальных параметров по минеральному составу удобрений были проведены испытания по обжигу гранулированных шламов в разных температурных режимах. В таблице 1 показаны результаты изменения минерального состава при различных параметрах обжига.

\section{Таблица 1}

Минеральный состав огарка при температуре обжига $600^{*}, 800^{* *}$ и $900^{\circ} \mathrm{C}^{* * *}$, масс \%

\begin{tabular}{|c|c|c|c|c|c|c|c|c|c|c|}
\hline \multirow{2}{*}{$№$} & \multicolumn{10}{|c|}{ Минеральный состав (прибл. вес. \%) } \\
\cline { 2 - 13 } & кварц & КПШ доломит & галит & сильвин & ангидрит & гематит & пироксен & *сингенит & слюда \\
\hline 1 & 10 & 18 & 8 & 5 & 4 & 44 & 2 & 13 & & 1 \\
\hline 2 & 9 & 15 & 5 & 3 & 4 & 40 & 2 & 19 & 2 & 1 \\
\hline 3 & 8 & 13 & 2 & 1 & 2 & 18 & 2 & 43 & 8 & \\
\hline
\end{tabular}

*Сингенит - $\mathrm{K}_{2} \mathrm{Ca}\left(\mathrm{SO}_{4}\right)_{2} \cdot \mathrm{H}_{2} \mathrm{O}$; анализ выполнен на дифрактометре SHIMADZU XRD-6000

Обжиг при температуре $600^{\circ} \mathrm{C}$ приводит к формированию новых для исходных шламов минералов (пироксен). При $800^{\circ} \mathrm{C}$ образуется пироксен и формируется сульфат калия и кальция (сингенит). Наиболее глубокие преобразования происходят при температуре $900^{\circ} \mathrm{C}$. Элементной базой для новообразований является ангидрит, количество которого уменьшается с $44 \%$ (при $600^{\circ} \mathrm{C}$ ) до $18 \%$ (при температуре обжига $\left.900^{\circ} \mathrm{C}\right)$ и в меньшей степени кварц, КПШ, доломит, галит и сильвин. Преобразование (разрушение) сильвина сопровождается уходом в возгоны хлора, вхождением калия в новообразованные минералы. Формируется бесхлорная основа новых удобрений [3].

Стерильность огарков позволяет рекомендовать проведение исследований по использованию их в качестве питательной среды для апикально-меристемного размножения картофеля на стадии размножения в теплицах после гидропонного выращивания микроклубней.

Для исследований по установленным оптимальным параметрам (обжига) были опробованы шламы БПКРУ-3 ПАО «Уралкалий», проанализирован их минеральный состав (табл. 2) и состав микроэлементов (табл. 3). 
Исходные шламы (пробы Б3 УЛТП-1, 2, 3, 4)

Таблица 2

\begin{tabular}{|c|c|c|c|c|c|c|c|c|c|c|}
\hline \multirow{2}{*}{$№$} & \multicolumn{8}{|c|}{ Минеральный состав (прибл. вес. \%) } \\
\cline { 2 - 12 } & кварц & галит & сильвин & КПШ & $\begin{array}{c}\text { доло- } \\
\text { мит }\end{array}$ & гипс & $\begin{array}{c}\text { анги- } \\
\text { дрит }\end{array}$ & слюда & хлорит & цеолит \\
\hline 1 & 4 & 51 & 9 & 12 & 8 & 11 & 2 & сл. & сл. & 3 \\
\hline 2 & 6 & 17 & 7 & 26 & 14 & 16 & 4 & 5 & 3 & 2 \\
\hline 3 & 7 & 9 & 3 & 26 & 17 & 26 & & 7 & 3 & 2 \\
\hline 4 & 5 & 11 & 4 & 24 & 25 & 16 & 5 & 7 & 3 & \\
\hline
\end{tabular}

Анализ выполнен на дифрактометре SHIMADZU XRD-6000, Cu-анод, графитовый монохроматор

Состав микроэлементов укрупнено-лабораторных проб

Таблица 3 исходных шламов (ЗБ УЛТП-1,2,3,4)

\begin{tabular}{|c|c|c|c|c|c|c|c|c|}
\hline № & $\mathrm{Cu}$ & $\mathrm{Zn}$ & $\mathrm{Zr}$ & $\mathrm{Mn}$ & $\mathrm{Ti}$ & $\mathrm{Fe}$ & $\mathrm{Sr}$ & $\mathrm{Rb}$ \\
\hline 1 & - & - & 39 & 372 & 1952 & 16802 & 196 & 41 \\
\hline 2 & - & 37 & 58 & 392 & 1769 & 22039 & 218 & 51 \\
\hline 3 & 54 & 52 & 60 & 628 & 3127 & 21887 & 369 & 46 \\
\hline 4 & - & 29 & 50 & 506 & 1979 & 20473 & 371 & 31 \\
\hline
\end{tabular}

Анализ выполнен на рентгенофлуоресцентном анализаторе INNOV-X, $\alpha$-серия, результаты приведены в ррm

Минеральный состав исходных шламов достаточно стандартный. Содержания микроэлементов отличаются. Содержания Fе составляют от 1,7 до 2,2\%. Содержания Тi от 0,17 до $0,31 \%$. Эти элементы можно квалифицировать, как попутные, и возможна оценка их практического использования. Количество железа корреспондируется с содержанием сульфидов, которые при обжиге преобразуются в оксиды железа. Формы нахождения титана, скорее всего, диоксиды титана. Содержания $\mathrm{Mn}$ и $\mathrm{Sr}$ колеблются в пределах сотых долей процента и они могут быть отнесены к собственно микроэлементам. Содержания $\mathrm{Cu}, \mathrm{Zn}, \mathrm{Zr}$ и $\mathrm{Rb}$ варьируют от 20 до 50 г/т.

Следующий этап исследований - комплексирование отходов калийного производства и отходов обогащения фосфоритов. Цель - получение комплексного по питательным компонентам удобрения. Были отобраны пробы отходов обогащения фосфоритов (эфелей) Верхнекамского месторождения фосфоритов, проанализирован их минеральный состав (табл. 4) и микроэлементы (табл. 5).

Таблица 4

Отходы обогащения фосфоритов (эфели)

\begin{tabular}{|c|c|c|c|c|c|c|c|}
\hline \multirow{2}{*}{$\begin{array}{c}\text { № } \\
\text { пробы }\end{array}$} & \multicolumn{7}{|c|}{ Минеральный состав (прибл. вес. \%) } \\
\cline { 2 - 8 } & кварц & гипс & апатит & сидоренкит & кальцит & слюда & пирит \\
\hline 1 & 8 & 34 & 24 & 15 & & 16 & 3 \\
\hline 2 & 8 & 26 & 39 & & 7 & 18 & 3 \\
\hline 3 & 40 & 13 & 22 & 8 & & 14 & 3 \\
\hline
\end{tabular}

Анализ выполнен на дифрактометре SHIMADZU XRD-6000, Cu-анод, графитовый монохроматор

Состав микролементов проб эфелей

Таблица 5

\begin{tabular}{|c|c|c|c|c|c|c|c|c|}
\hline № & $\mathrm{Zn}$ & $\mathrm{As}$ & $\mathrm{Cr}$ & $\mathrm{Zr}$ & $\mathrm{Mn}$ & $\mathrm{Fe}$ & $\mathrm{Sr}$ & $\mathrm{Rb}$ \\
\hline 1 & 75 & 49 & - & 91 & 745 & 80024 & 817 & 96 \\
\hline 2 & 59 & 48 & - & 174 & 704 & 99317 & 504 & 123 \\
\hline 3 & 20 & - & - & 25 & 109 & 2404 & 389 & - \\
\hline
\end{tabular}

Анализ выполнен на рентгенофлуоресцентном анализаторе INNOV-X, $\alpha$-серия, результаты приведены в ppm 
Минеральный состав эфелей достаточно близок шламам, за исключением собственно фосфорных минералов апатита и сидоренкита. В составе микроэлементов отсутствует титан. Характерно более высокое содержание железа.

Пробы шламов прошли стадию обогащения и грануляции с последующим высокотемпературным обжигом (3 пробы). Материал 4-й пробы был смешан с пробами эфелей в соотношении 3:1. Далее материал смешанной пробы также прошел стадию грануляции и обжига при температуре $900^{\circ} \mathrm{C}$. Был получен экспериментальный образец комплексного калий-фосфорного огарка. Далее был произведен анализ минерального состава огарка (табл. 6) и содержания микроэлементов (табл. 7).

Содержание микроэлементов в шламах и огарках практически не меняется. Меняется форма нахождения микроэлементов. В исходном шламе все микроэлементы находятся в форме сульфидов [4]. После высокотемпературного обжига, который способствует отжигу сульфидов, образуются оксиды, содержащие или включающие микроэлементы. В свою очередь микроэлементы в оксидной форме прочно адсорбируются на минеральной матрице огарка, что способствует постепенному их поступлению в почву и постепенному усвоению растениями.

Несколько слов о так называемых балластных минералах огарка.

Более половины состава огарка составляют содалит, акерманит, пироксен. Поскольку катионная часть этих минералов представлена $\mathrm{Mg}$ и Сa, они также являются мелиорирующими компонентами. Поэтому разрушение доломита в продуктах высокотемпературного обжига не влияет на мелиорирующие свойства полученного удобрения (огарка). Это означает переход на другие мелиорирующие компоненты (содалит, акерманит, пироксен), период разрушения которых значительно больше доломита. Иначе говоря, огарок представляет собой комплекс, включающий все три компонента - питательные, мелиорирующие и микроудобрения, что намного понижает его себестоимость. С учетом новых свойств, приобретенных после обжига, пролонгированность действия мелиорантов, заключенных в огарке, достаточно велика.

В случае с азотистыми соединениями обжиг приводит к «уходу» азота в виде аммиака.

Поэтому азотистые соединения возможно комплексировать только в виде неразрушающихся при высокой температуре соединений (возможно в виде жидких аммонийных отходов).

Таблица 6

Огарки из шламов* и смеси шламов и эфелей**

\begin{tabular}{|c|c|c|c|c|c|c|c|c|c|}
\hline \multirow{2}{*}{$\begin{array}{c}\text { № } \\
\text { пробы }\end{array}$} & \multicolumn{9}{|c|}{ Минеральный состав (прибл. вес. \%) } \\
\cline { 2 - 11 } & кварц & галит & сильвин & $\begin{array}{c}\text { акер- } \\
\text { манит }\end{array}$ & содалит & $\begin{array}{c}\text { пиро- } \\
\text { ксен }\end{array}$ & КПШ & $\begin{array}{c}\text { анги- } \\
\text { дрит }\end{array}$ & апатит \\
\hline $1^{*}$ & 4 & 12 & 14 & 29 & 6 & 22 & 10 & 3 & \\
\hline $2 *$ & 6 & 5 & 8 & 23 & 11 & 31 & 12 & 5 & \\
\hline $3 *$ & 7 & 3 & 6 & 39 & 4 & 17 & 17 & 6 & \\
\hline $4^{* *}$ & 11 & 4 & 5 & 35 & 5 & 15 & 9 & 4 & 13 \\
\hline
\end{tabular}

Анализ выполнен на дифрактометре SHIMADZU XRD-6000, Cu-анод, графитовый монохроматор

Таблица 7

Состав микроэлементов огарков

(* без примеси эфелей;** с примесью эфелей)

\begin{tabular}{|c|c|c|c|c|c|c|c|c|c|c|c|c|}
\hline № & $\mathrm{Cu}$ & $\mathrm{Zn}$ & $\mathrm{Ni}$ & $\mathrm{Pb}$ & $\mathrm{Sn}$ & $\mathrm{Cr}$ & $\mathrm{Zr}$ & $\mathrm{Mn}$ & $\mathrm{Ti}$ & $\mathrm{Fe}$ & $\mathrm{Sr}$ & $\mathrm{Rb}$ \\
\hline 1 & 72 & 40 & - & 32 & 274 & - & 66 & 369 & 1717 & 21282 & 287 & 35 \\
\hline 2 & - & 57 & 127 & - & 206 & - & 79 & 632 & 2436 & 28531 & 310 & 55 \\
\hline 3 & - & 70 & 94 & 19 & - & 251 & 78 & 646 & 3380 & 28161 & 499 & 55 \\
\hline 4 & 79 & 109 & 150 & 58 & 178 & - & 89 & 1094 & - & 43073 & 657 & 58 \\
\hline
\end{tabular}

Анализ выполнен на рентгенофлуоресцентном анализаторе INNOV-X, $\alpha$-серия, результаты приведены в ррm 


\section{Заключение}

Разработана программа и методика лабораторных предварительных испытаний экспериментальных партий комплексных удобрений пролонгированного действия и лабораторных образцов (К-P).

Получила дальнейшее развитие методология аналитических исследований, позволяющая получить информацию о минеральном составе, составе минераловпримесей и примесей микроэлементов в исходных шламах, продуктах их переработки.

Испытания образцов с добавками отходов переработки фосфоритовых руд включили определения минерального состава по данным рентгенофазового анализа и состава микроэлементов по данным рентгено-флюоресцентного метода.

Исследования, проведенные в 2018 году, показали, что комплексные удобрения пролонгированного действия по эффективности воздействия на агрохимические свойства почв Пермского края, урожайность картофеля и качество клубней не уступают традиционным (хлористый калий) удобрениям.

В соответствии с методикой испытания лабораторных образцов в полевых условиях, разработанной в 2017 г. в рамках КПНИ, осуществлен вариант испытания экспериментальной партии удобрений осенью под зяблевую вспашку (2018 г.), под посадку картофеля в 2019 г.

Содержание и результаты проведенных научных исследований соответствуют тематике разделов КПНИ «Развитие селекции и семеноводства картофеля», также являются базой для осуществления комплексного плана научных исследований ПФИЦ УрО РАН на 2019-21 гг.

\section{РЕКОМЕНДАЦИИ}

Необходимо расширение опытного производства комплексных удобрений пролонгированного действия в двух направлениях:

1) получение объемов удобрений, позволяющих проводить как лабораторные, так и микроделяночные и полевые испытания, а также испытания в фермерских хозяйствах;

2) расширение свойств удобрений по комплексности питательных компонентов (KР) и увеличение объемов получения таких комплексных удобрений;

3) расширение научно-производственной и аналитической базы;

4) проведение экспериментов по созданию К-Р огарков с равным соотношением калия и фосфора; для этого можно использовать фосфориты (исходные).

\section{БИБЛИОГРАФИЧЕСКИЙ СПИСОК}

1. Оносов Д.В., Сметанников А.Ф. Разработка технологии комплексной утилизации отходов переработки калийно-магниевых руд // Проблемы безопасности и эффективности освоения георесурсов в современных условиях: материалы науч.-практ. конф., посвящ. 25-летию Горн. ин-та УрО РАН и 75-летию основателя и первого директора ин-та чл.-корр. РАН А.Е. Красноштейна / ГИ УрО РАН. - Пермь, 2014. - С. 167-171.

2. Бачурин Б.А., Сметанников А.Ф., Хохрякова Е.С. Эколого-геохимическая оценка продуктов переработки глинисто-солевых шламов калийного производства // Современные проблемы науки и образования: электр. науч. журн. - 2014. - № 6. - Режим доступа: www.science-education.ru/120-15442. (дата обращения: 19.11.2014).

3. Сметанников А.Ф., Косолапова А.И., Митрофанова Е.М., Бачурин Б.А., Оносов Д.В., Фомин Д.С., Ямалтдинова В.Р., Шишков Д.Г. Оносова Е.Ф. Результаты испытаний отходов переработки калийномагниевых руд в качестве удобрений пролонгированного действия // Вестн. Перм. науч. центра. 2017. - № 4. - С. 58-63.

4. Капиллярно-электролитический способ извлечения микро-и наночастиц соединений металлов из тонких фракций горных пород, руд и техногенных продуктов: пат. 2659871 Рос. Федерация: МПК В 82 В 3/00 (2006.01) / Сметанников А.Ф., Оносов Д.В.; патентообладатель: ПФИЦ УрО РАН. - № 2016150221. заявл. 20.12.2016; опубл. 04.07.2018. - Бюл. № 19. 